\title{
A case of bipartite patella and vastus notch from Kneževići hillfort - Malo Libinje,
}

\section{Croatia}

\author{
Barbara Kriletić ${ }^{1}$, Morana Vuković ${ }^{2} \&$ Mario Carić ${ }^{3}$ \\ ${ }^{1}$ No institutional affiliation, Zagreb, Croatia, krileticbarbara@gmail.com \\ ${ }^{2}$ Archaeological Museum Zadar, Croatia, mvukovic@amzd.hr \\ ${ }^{3}$ Centre for Applied Bioanthropology, Institute for Anthropological Research, Zagreb, Croatia, mario.caric@inantro.hr \\ * Corresponding author: krileticbarbara@gmail.com
}

Received July $13^{\text {th }}, 2021$

Accepted for publication December $6^{\text {th }}, 2021$

Online First December $6^{\text {th }}, 2021$

Keywords: Concave defects, bipartite patella, vastus notch, skeletal remains, Late Iron Age, bioarchaeology.

\section{Abstract}

Here we present six adult patellae with superolateral concave defects observed amongst the remains of at least 28 individuals retrieved from four Late Iron Age burials from Kneževići hillfort - Malo Libinje, Croatia. The right patella of an adult individual displays a rough-edged concave defect on superolateral side of the bone called bipartite patella. Other five patellae show concave defects with smooth edges also located on superolateral side; a defect known as vastus notch. Though physically similar, the two conditions are etiologically distinct. A large amount of observed cases of vastus notch in this assemblage may indicate that these individuals frequently performed activities involving kneeling and/or squatting. This is the first documented case of joint occurrence of bipartite patella and vastus notch in a Croatian skeletal assemblage, but also the largest amount of patellae with vastus notch in an archaeological population from Croatia recorded so far.

\section{Introduction}

Bipartite patella is a congenital condition caused by incomplete ossification of the bone. The condition usually remains asymptomatic and is most commonly diagnosed as an accidental finding (Okuno et al., 2004). First reported case of bipartite patella, discovered during an autopsy, was noted by Gruber (1883). Since then, more cases have been described in clinical as well as bioarchaeological literature (Wright, 1903; Adams \& Leonard, 1925; Paal, 1932; Blumensaat, 1933; George, 1935; Stuke, 1950; Shulman, 1955; Resnick \& Niwayama, 1981; Tachdjian, 1990; Silverman \& Kuhn, 1993; Duthie \& Bentley, 1996). In 1921, Saupe provided the first classification of bipartite patella, dividing it in three types according to the location of the secondary ossification center (Saupe, 1921). Type I involves the inferior pole of the bone with relative prevalence of $5 \%$; type II (20\%) involves the lateral side and has longitudinal expression; type III (75\%) involves superolateral portion (Mesina \& Sineo, 2007). Most recently, a new classification of bipartite patella was proposed by Oohashi and colleagues (2010), based on both location and number of fragments. They excluded inferior pole from the classification and included two more subtypes based on more than two fragments (the so-called 'tripartite patella'). In general, the condition is nine times more common in males than in females (Rich et al., 2005); however, different studies recorded different male/female ratios ranging from 2.1:1 to 4.3:1 (Weaver, 1977; Ogata, 1994; Kavanaugh et al., 2005; Oohashi et al., 2010; O'Brien et al., 2011). Bipartite patella occurs bilaterally in about $43 \%$ of cases (Green, 1975).

Bipartite patella is profoundly similar and thus frequently confused with a defect called vastus notch. Continued contraction associated with the flexion of 
the knee induces impression on the superolateral side of the patella, referred to as a vastus notch (Messeri, 1961). Two conditions are macroscopically similar yet occur by a different cause. A presence of a depression in the upper portion on the outer margin of the ancient Egyptian's patella was first mentioned by Kempson (1902) who stated that this was a common variation of the patella. Oetteking (1922) also examined a patella (no. 697 from Chihuahua, Mexico) with a deep superolateral notch, which he compared to Kempson's finding. Messeri (1961) recorded high frequency of this marker in Neolithic populations from northern Italy, and suggested that this was due to continuous tension

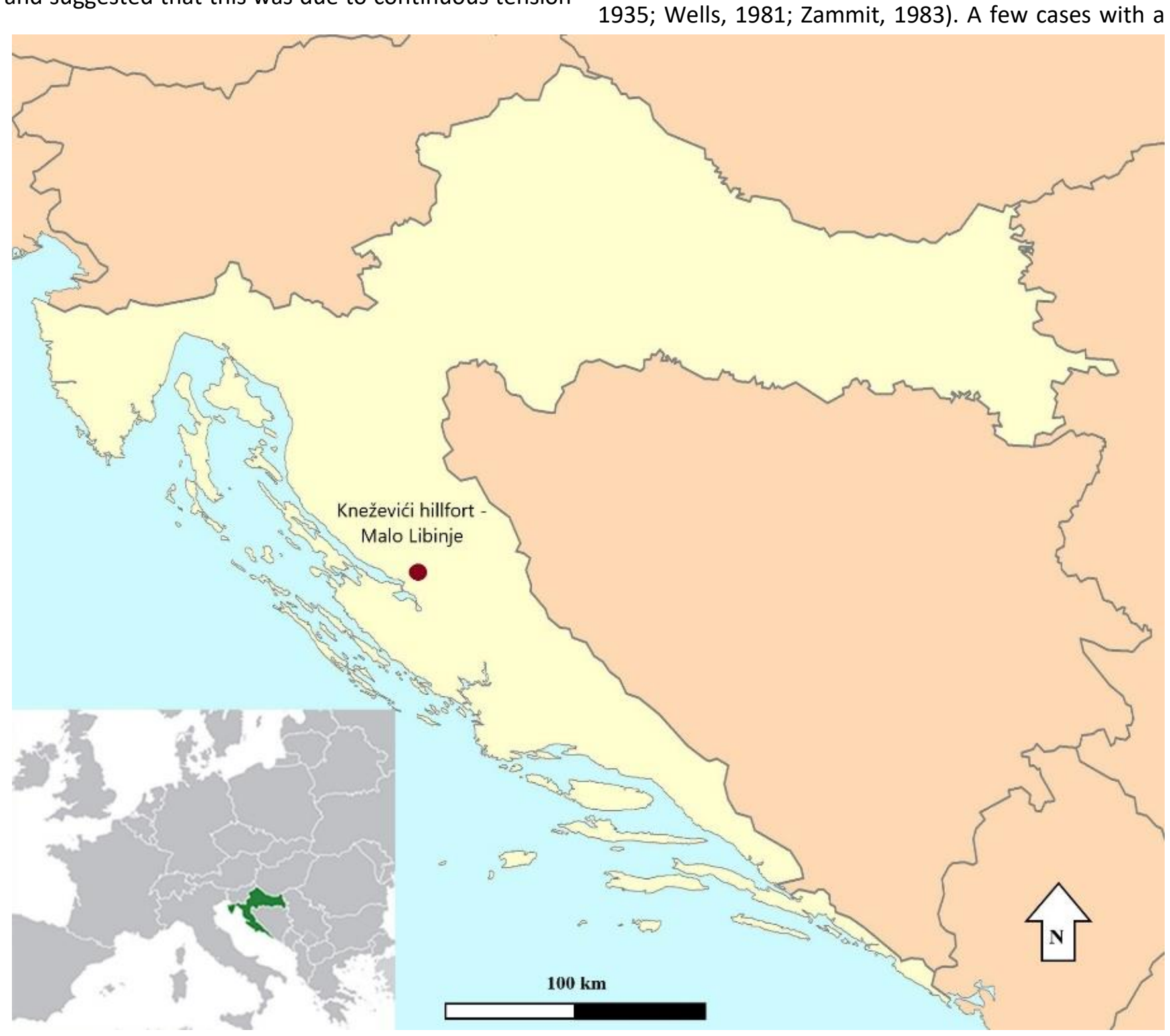

of the vastus lateralis muscle associated with squatting and/or kneeling. Since then, the condition is known as the vastus notch. Afterwards, vastus notch was mentioned and described by several authors (e.g. Mann \& Murphy, 1999; Anderson, 2002; Inskip, 2013; Molleson, 2016; Bedić, 2017). There is a lack of evidence of the most probable cause of bipartite patella and vastus notch, especially if the conditions have a genetic component, but future studies may elucidate this matter further.

Bipartite patella and vastus notch are not common findings in archaeological populations (Baudounin, 1935; Wells, 1981; Zammit, 1983). A few cases with a

Figure 1. Map of Croatia with Kneževići hillfort - Malo Libinje site. 
small prevalence of the conditions have been reported (e.g. Anderson, 1963; Finnegan, 1978; Mullen \& Hoppa, 1992; Anderson, 2002; Kjellstrom, 2004; Messina \& Sineo, 2007; L'Abbé et al., 2008; Stephan \& Gill, 2016; Rios et al., 2018), without further examination through radiographs. Bilateral knee radiographs were acquired only on modern population to investigate the prevalence of two conditions, symptoms and treatments, if possible (Kose et al., 2015; Sim et al., 2016).

Among the skeletal remains, six adult patellae with superolateral concave defect were unearthed during the excavations of Kneževići hillfort - Malo Libinje site in 2020; a highly uncommon occurrence in terms of prevalence in such a small sample. The aim of this study is a detailed presentation of cases recorded in Malo Libinje and comparison with similar ones from both archaeological and clinical contexts. In addition, the differential diagnosis will try to identify if these conditions indeed represent bipartite patella and vastus notch or some other pathological lesions, and what the potential causes of these conditions are.

\section{Materials and methods}

An Iron Age settlement surrounded by a rampart and a necropolis chronologically ascribed to the 6th century BCE (Glavičić, 1984) on the south slope, Kneževići hillfort is located next to Malo Libinje field in South Velebit Mountain in Zadar County, Croatia (Figure 1). At the beginning of the 20th century, a single grave was excavated at the bottom of the hillfort. Further excavations were not conducted until the 1980s, when another grave was unearthed near the first. Archaeologists also discovered a few tumuli nearby the hillfort, as well as on the field nearby on the East, Gornje polje (Glavičić, 1982, 1982a, 1984). Systematic research began in 2018 and was conducted by the Archaeological Museum in Zadar. The osteological finds were found in four burials; in the revision excavations of two burials (G1 and G2) and in newfound graves (G3 and T1G1). Three graves were unearthed in the necropolis

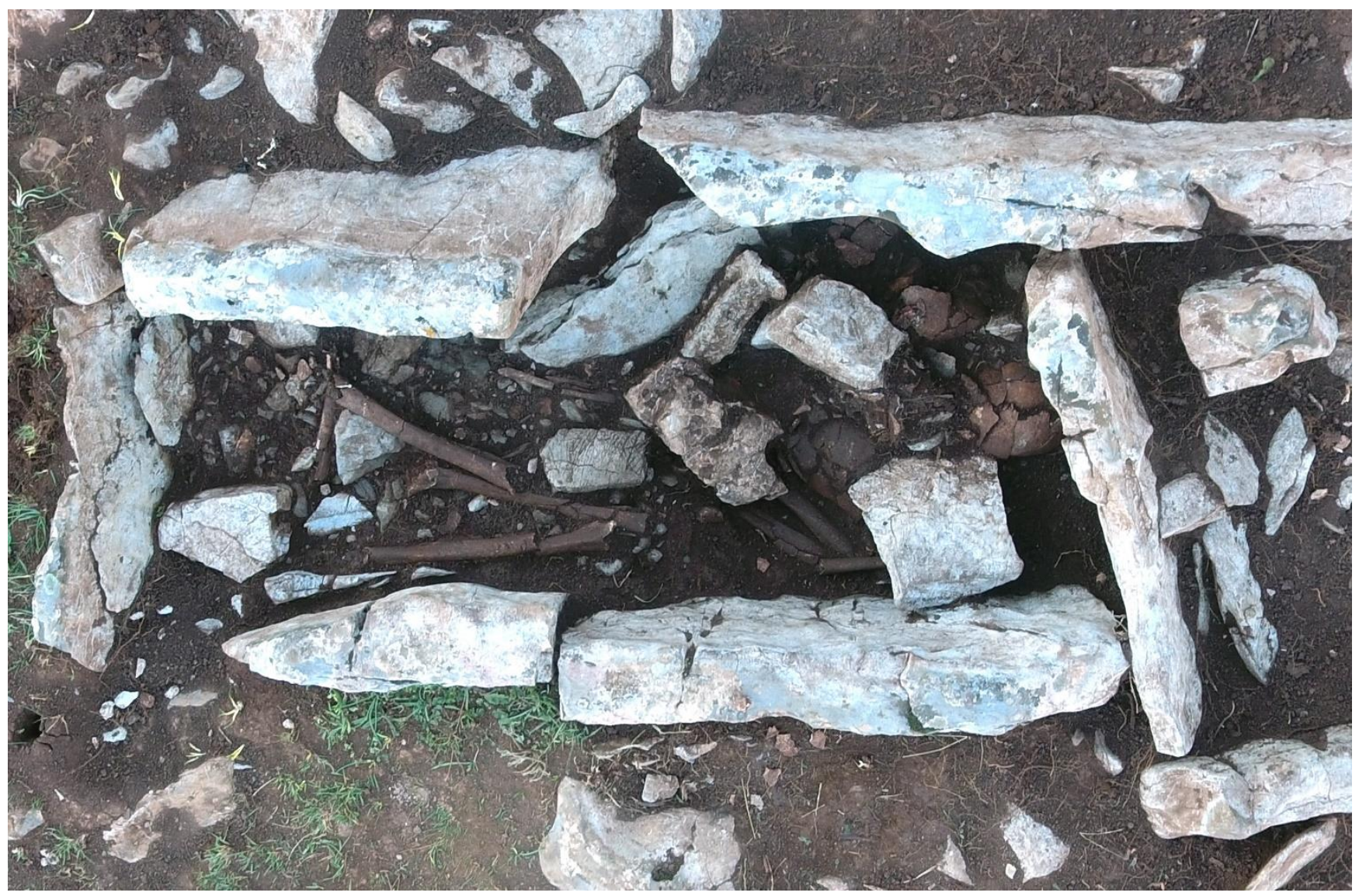

Figure 2. The grave in the tumulus; a burial in a rectangular stone chest. 
underneath the hillfort and one in the newfound tumulus on the East side near the hillfort. Grave 1 (G1) was a burial in a rectangular stone chest, while Graves 2 and 3 (G2 and G3) were constructed out of amorphous stone. The grave in the tumulus (T1G1) was also a burial in a rectangular stone chest (Figure 2). All burials except $G 2$ contained the remains of several individuals. The remains in the graves were randomly assembled, overlying one another. The archaeological context suggests that burials in G1, G3 and tumulus grave could represent family tombs.

The skeletal remains presented in this paper were analyzed at the Laboratory for Evolutionary Anthropology and Bioarchaeology of the Institute for Anthropological Research in Zagreb. Since the human remains from Malo Libinje were commingled and highly fragmented, it was not possible to analyze individual skeletons. Therefore, a minimum number of individuals (MNI) was established by using the methodology described in the volume edited by Osterholtz and colleagues (2014).

In this study, sex estimation was conducted using the discriminant analysis of patella measurements due to heavy fragmentation of skeletal remains, with approximately 60-80\% accuracy (Indra et al., 2021). Following the protocol of Dayal and Bidmos (2005), six variables from the patella were recorded using a standard sliding caliper. The patellae measurements from the Malo Libinje individuals were also compared with other, morphologically most similar populations: contemporary Spanish population (Peckmann et al., 2016), Southern Italians (Introna Jr. et al., 1998), and Medieval Germans (Kemkes - Grottenthaler, 2005).

Age-at-death was possible to establish only for subadults based on the development and formation of deciduous and permanent teeth and the degree of bone ossification (Fazekas \& Kósa, 1978; Scheuer \& Black, 2000). Subadult individuals were categorized into three groups: newborns, infants, and small children (0-5 years); older children (6-11 years) and adolescents (1218 years). Due to heavy fragmentation and weathering the precise age-at-death for the adults could not be established. Therefore, all adults were pooled into one group. All bones were comprehensively examined for pathological conditions, according to Ortner's (2003) and Aufderheide \& Rodriguez-Martin's (1998) identification of pathologies.

\section{Results}

The MNI in the Kneževići - Malo Libinje assemblage is 28 (19 adults and nine subadults). G1 contained the remains of at least eight adults and four subadults. G2 contained the remains of a very fragmented and poorly preserved skeleton of an adult individual. In G3, the remains of at least five adults and one subadult were interred. And finally, the $\mathrm{MNI}$ in the grave from the tumulus was concluded to be nine. The discriminant

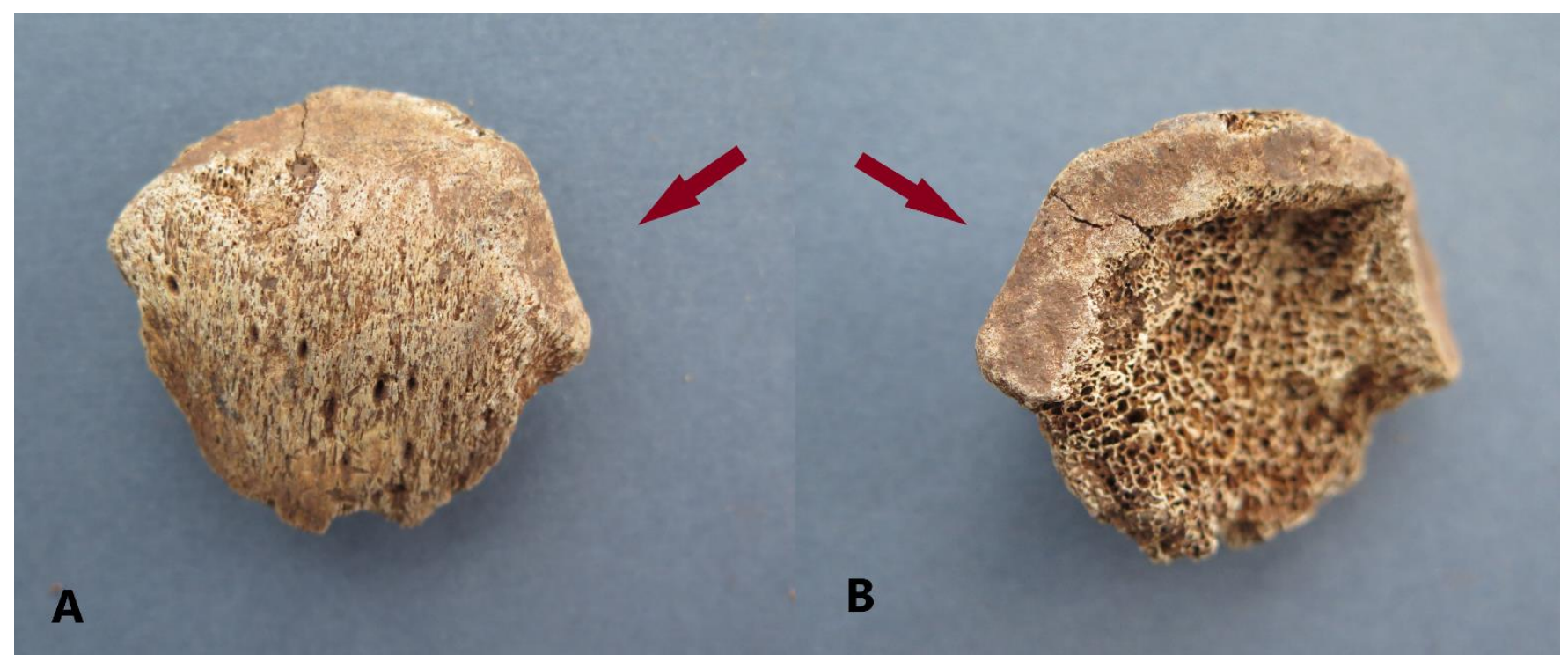

Figure 3. Patella A with vastus notch, anterior (A) and posterior view (B). 


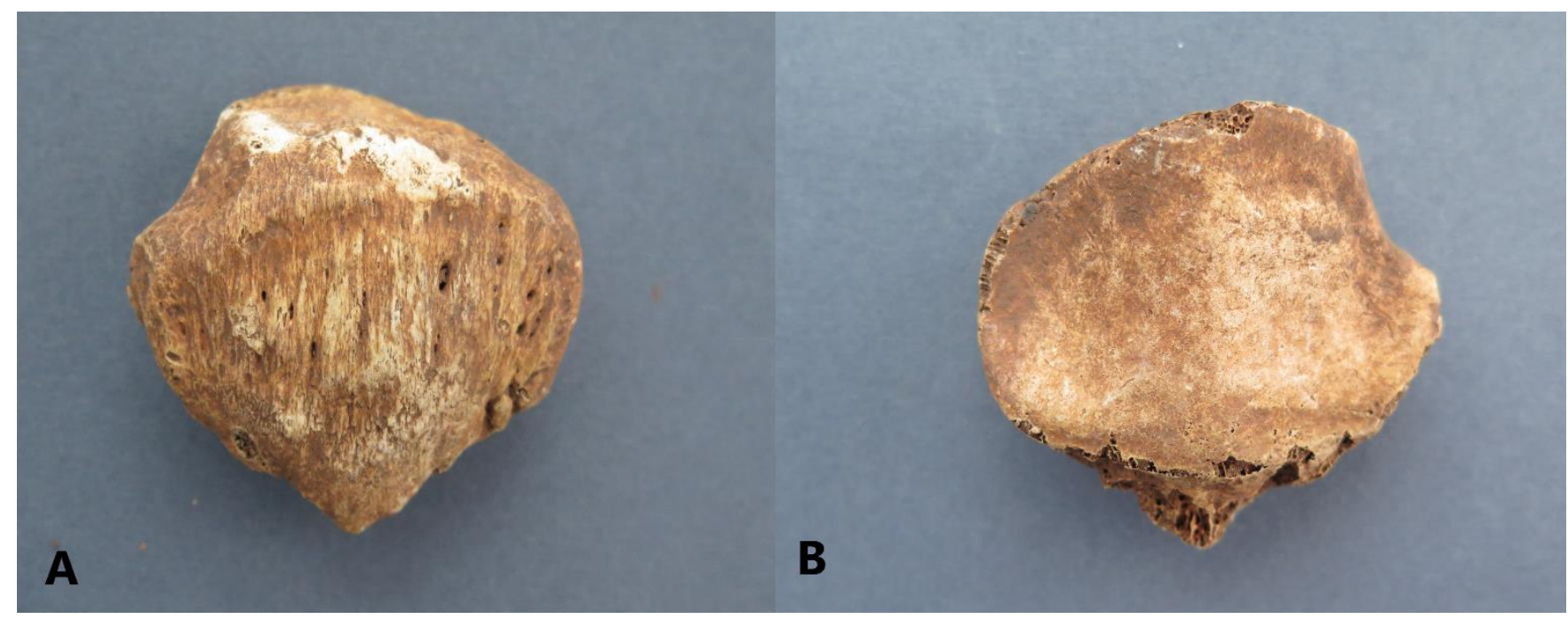

Figure 4. Patella $B$ with vastus notch, anterior (A) and posterior view (B).

analysis of patella measurements from Malo Libinje indicates that three most probably belonged to females (patellae A, C, and D) and three to males (patellae B, E, and $\mathrm{F}$ ).

As far as pathological conditions are concerned, the following were observed: porotic hyperostosis, cribra orbitalia, osteomas, blunt and sharp force traumas, abscesses, caries, Schmorl's nodes, degenerative osteoarthritis, vastus notch, and bipartite patella. However, these conditions, apart from vastus notch and bipartite patella, will be described and comprehensively discussed in a separate study.

Six out of nine patellae available for the analysis displayed an incomplete ossification on the superolateral side of the bone. In G1, there were two patellae belonging to two adult individuals; one smaller, left patella (Patella A), very fragmented on the posterior side of the bone, and one larger, right patella (Patella B), which was well preserved. Patella A shows mild tendon ossification on the anterior surface - a feature

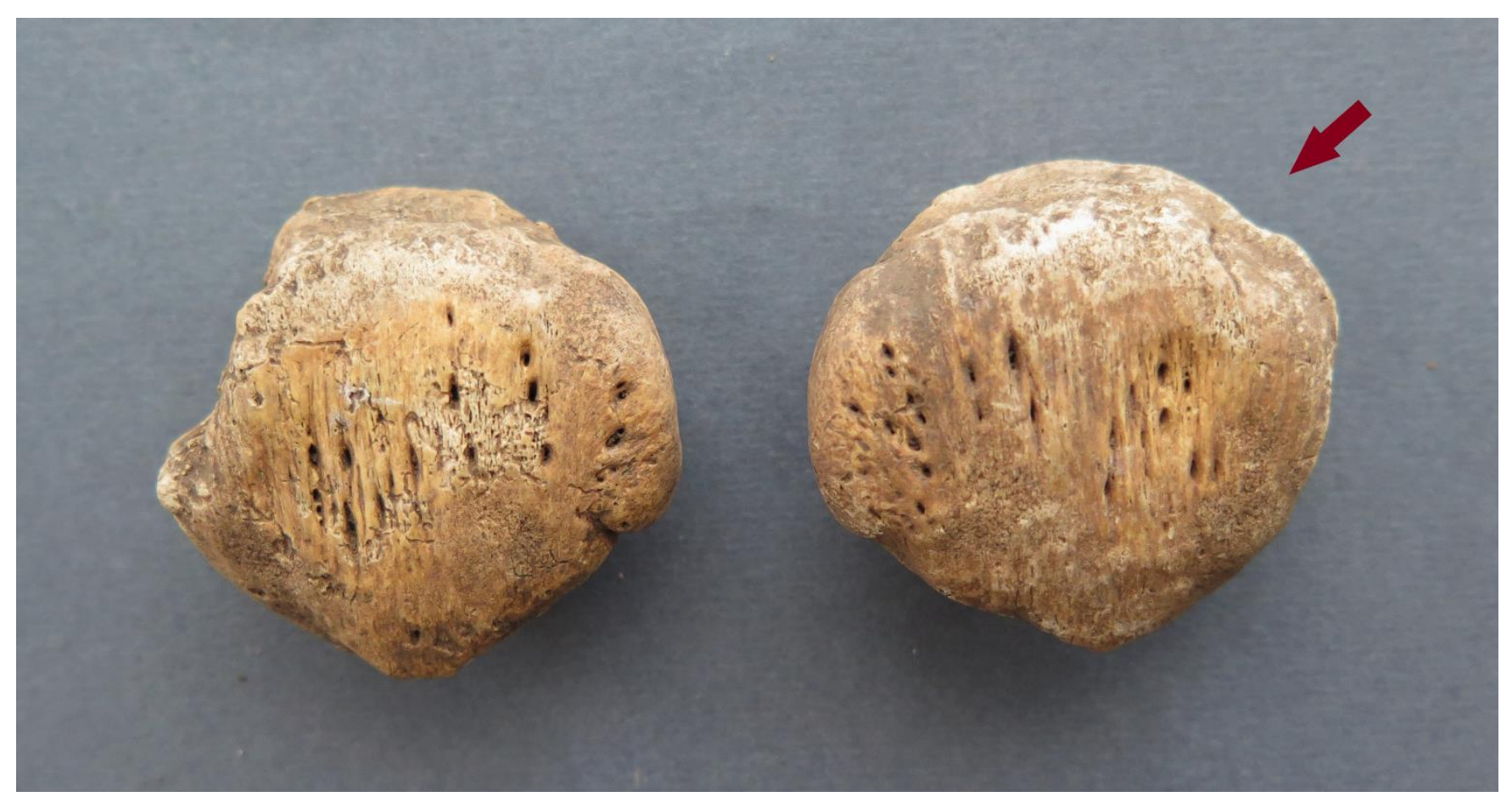

Figure 5. The pair of patellae; patella $C$ with vastus notch and bipartite patella $D$. 


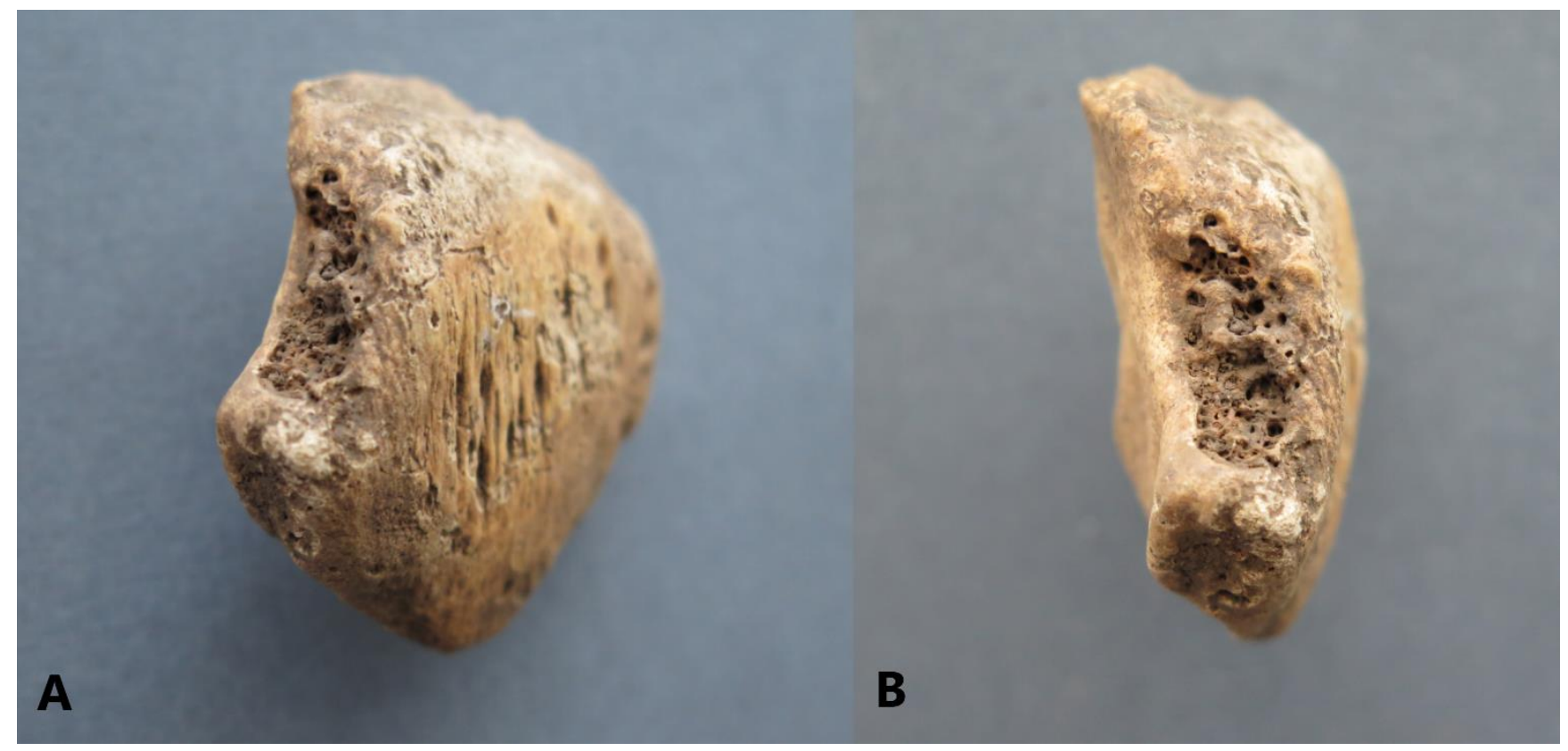

Figure 6. Bipartite patella $D$, anterior $(A)$ and posterior view (B).

typically recorded as an activity marker - while its superolateral side shows indications of a concave defect with smooth edges (Figure 3). Patella B shows more severe tendon ossification than Patella A (Figure 4). The concave defect on superolateral side is also more accentuated, especially on the posterior end, but the edges retain their smoothness.

In G3, there were four patellae with concave defects, two left and two right, belonging to three adults. Two patellae from the group (Patellae $C$ and $D$ ) seem to be a pair since they are identical and slightly smaller in size than the other two (Patellae E and F). The left patella from the pair (Patella C) shows moderate concave defect on the superolateral side with smooth edges (Figure 5). The right patella (Patella D) shows substantial concave defect on the superolateral side the borders of the defect are porous and thick, different from the other patellae from Malo Libinje (Figure 6). Both patellae are well preserved and show mild tendon

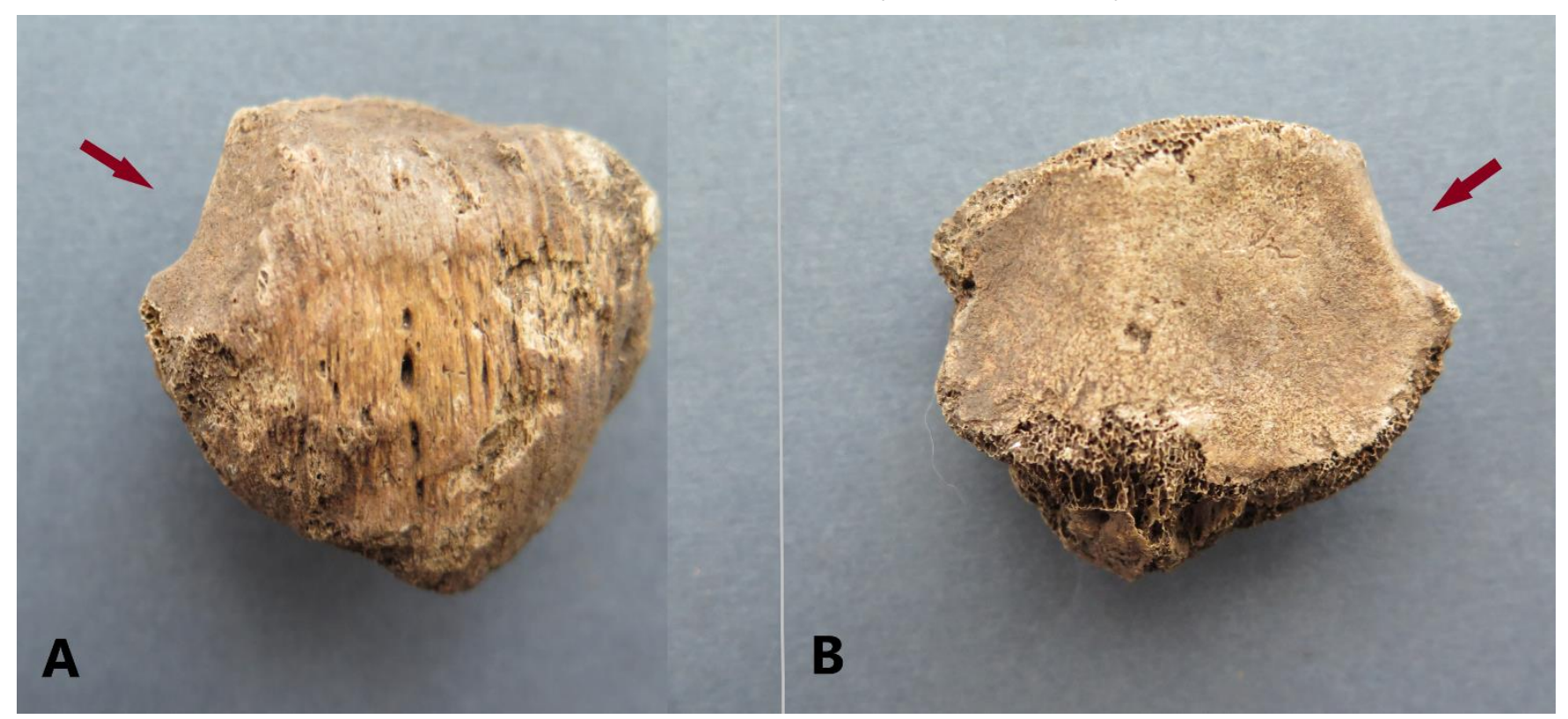

Figure 7. Patella E with vastus notch, anterior (A) and posterior view (B). 


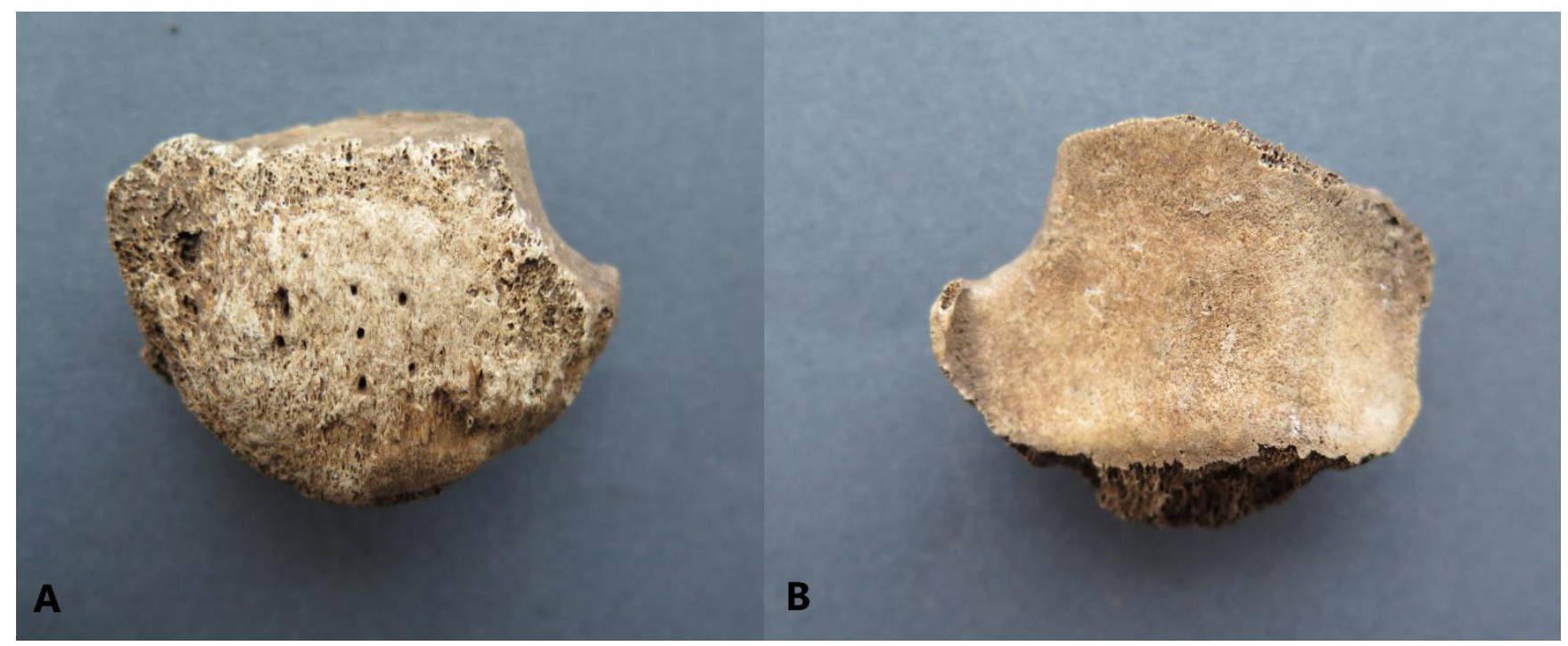

Figure 8. Patella F with vastus notch, anterior (A) and posterior view (B).

ossification on the anterior surface. The other, larger, right patella (Patella E), is well preserved with slight porosity on the superior and inferior sides and moderate tendon ossification on the anterior surface the concave defect is located on the superolateral side; the edges are smooth with porous, accentuated tip on the posterior end (Figure 7). The cortex of the last, left patella (Patella $\mathrm{F}$ ) is badly preserved and there is visible tendon ossification on the anterior surface (Figure 8). On the superolateral side, the concave defect is accentuated, with pronounced osteophytosis on the posterior end.

\section{Discussion and Conclusion}

\section{Discussion}

In this study, two physically similar but etiologically distinct conditions were recognized. Six patellae from Malo Libinje display superolateral concave defects, a relatively rare finding in archaeological populations (Messina \& Sineo, 2007). These defects were diagnosed as bipartite patella and vastus notch.

Patella $\mathrm{D}$ has a porous, roughed-edged lesion known as bipartite patella. It is a condition where patella is composed of two separate bones. Based on the location of the secondary ossification center, it is possible to diagnose Patella D as bipartite patella type III (Saupe, 1921). Secondary ossification centers of the patella appear around twelve years of age (Ogden, 1984), and if they later fail to merge, a bipartite patella develops.
Separate ossicle may stay detached or can fuse incompletely (Green, 1975). In Patella D's case from Malo Libinje, the ossicle is detached and is not present, as it often occurs in skeletal assemblages. Some authors suggest mechanical stress (Oetteking, 1922) or repeated microtrauma (Todd \& McCally, 1921; Green, 1975 ) as possible causes. Usually, bipartite patella is considered asymptomatic (Atesok et al., 2008). In some cases, it is a source of persistent pain and can even cause complete disability in the knee (Messina \& Sineo, 2007). In treatment of painful patella, the most common surgical approach is excision of distressing fragment (Weckström et al., 2008).

The oldest known example of bipartite patella dates back to 49,000 years ago to the Neandertals from El Sidrón cave (Spain) where a small, probably left tripartite patella with separate ossification center located inferiorly was recovered (Rios et al., 2019). Since bipartite patella with separate ossification center located superolaterally is the most common morphological variant, such a condition is even rarer. Another example of bipartite patella from archaeological context was recorded at the Palaeochristian necropolis of San Giovanni in Marsala, Sicily (Messina \& Sineo, 2007). This left patella shows lack of ossification on the lateral side, which can be diagnosed as bipartite patella type II (Saupe, 1921). Furthermore, a bipartite patella was discovered in a skeleton of a 13-15 years old juvenile from the 
cemetery associated with Franciscan friary at St. Faith's Lane in Norwich, England dated between the 13th and 16th century CE (Anderson, 2002). In this case the fracture line is clearly visible on the right patella and the resultant ossicle is fused incompletely (Anderson, 2002). The bipartition of the patellae of two skeletons from Pilanesberg National Park, South Africa dated to the Late Iron Age (ca 1300 to $1820 / 1830$ CE) show that this condition can also occur bilaterally (L'Abbé et al., 2008). And finally, Anderson (1963) recorded very high prevalence (8\%) of bipartite patella in a Canadian Iroquois ossuary dating back to $1400 \mathrm{CE}$.

In modern populations, bipartite patella is usually discovered through knee radiographs. One of the studies involved analysis of the radiographs in Turkish patients in order to determine the prevalence of bipartite patella and analyze the differences between sex and laterality (Kose et al., 2015) concluded that there is a prevalence of around $1 \%$ of the condition being more frequently found in males, and mostly on the superolateral side. A similar study was conducted using magnetic resonance imaging (MRI) to determine the prevalence of bipartite patella and perform analysis of this rare condition (Akdag et al., 2019). This study confirmed that the condition occurs mainly in males and more frequently on the superolateral side, and that the overall prevalence is found to be $0.8 \%$ (Akdag et al., 2019). However, true prevalence of bipartite patella is still uncertain. Different authors reported different data: Green (1975) states that the prevalence of the condition is $0.2-6.0 \%$ while others say it may affect 1 $3 \%$ of a population (Todd \& McCally, 1921; Adams \& Leonard, 1925; Tachdjian, 1990; Aufderheide \& Rodriguez-Martin, 1998). There is a wide variation in prevalence in different ethnic groups, and sometimes high percentage can be the result of close kinship (Kose et al., 2015). Since the condition is mostly asymptomatic and a rare find in archaeological excavations, it is no surprise that a true prevalence can be difficult to determine.

Five other patellae from Malo Libinje show a condition called the vastus notch. This anatomical variant occurs due to continuous contraction of the vastus lateralis muscle of the femoral quadriceps (Capasso et al., 1999). It is associated with chronic knee flexion, i.e. squatting.
Vastus notch appears as a slight or a deep concavity, frequently with the processus spinosus located at the inferior margin of the notch which marks the lower limit of the tendon (Oetteking, 1922). It is commonly mistaken for bipartite patella because it also occurs on superolateral side of the bone. The two conditions can be distinguished due to fact that vastus notch is smooth-edged (Mann \& Murphy, 1990) as opposed to the porous surface with visible trabecular bone on bipartite patella. A separate ossicle can only occur if the patella is bipartite, detached or incompletely fused, and never associated with vastus notch. The pair of patellae (C and D) from G3 are especially interesting since the left one exhibits a vastus notch while the right one is bipartite.

According to the available bioarchaeological literature, vastus notch occurs a bit more frequent than bipartite patella. In Croatia it was recorded at several sites: the earliest example was observed on the right patella of an adult male from the Late Bronze Age cremation cemetery of Poljana Križevačka 2, dated to the 13th century BCE (Premužić, 2016); the second case was recorded again on the right patella of an adult male, this time in Glagoljaška Street in Zadar, dated to the Late Roman Period (Bedić, 2017). Another case was registered at the Sokol fortress in Konavle, dated to the Late Antiquity (6th century CE) (Topić et al., 2019). And finally, two cases were observed on the left patella of an adult male and the right patella of an adult female from Pakoštane - Maksanova gomila site, dated between the Late Middle Ages and the Early Modern Period (15th-16th century CE) (Šućur et al., 2020).

Opposite to bipartite patella, vastus notch occurs mostly due to repetitive activity. It is associated with chronic and consistent kneeling and squatting (Capasso et al., 1999). There are but few studies focusing on this lesion occurring in archaeological populations. For example, in a study of human skeletal remains from the early Neolithic settlement (10500-8400 BP) of Nemrik in Tigris Valley Molleson (2006) recorded the occurrence of small vastus notch in patellae of three individuals suggesting that the squatting on the heels could be a resting position, although the condition could also be induced by sartorial position. Furthermore, a small patella of a young female from the Neolithic settlement 


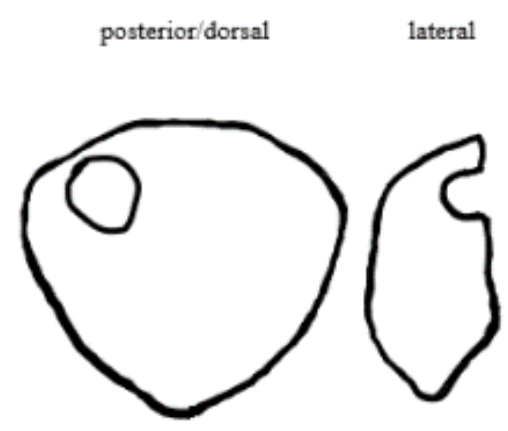

I Dorsal defect

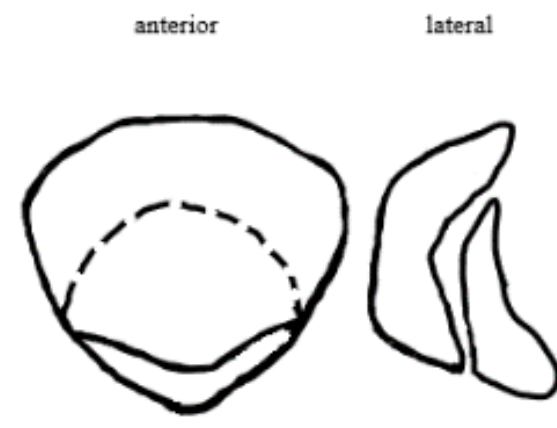

II Double patella

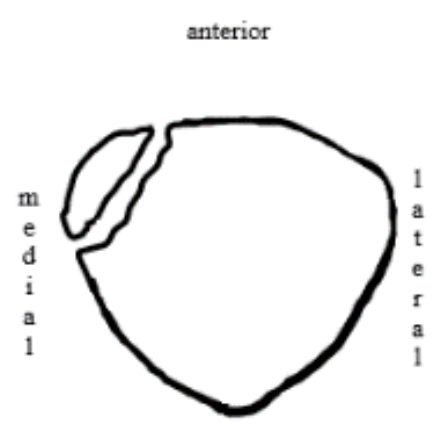

III Separate ossicle on the medial border

Figure 9. Defects mistaken for bipartite patella and/or vastus notch; schematics.

of Abu Hureyra in Syria displays vastus notch on the superolateral border suggesting that she as well as the other women from the group may have squatted in the 'hocker' position to carry out the certain tasks (Molleson, 2016). And finally, the study of various Islamic period skeletal assemblages from Medieval Iberia Habitual indicates that the adoption of praying resulted in patella alterations and development of vastus notch (Inskip, 2013).

Prehistoric people cultivated a whole range of domestic cereals which required mechanical preparation before they could be eaten. The preparation of grain such as grinding and dehusking was the most demanding and labor-intensive activity, and it usually took much time. Since the seed could not be kept once dehusked, the grain had to be pounded every day (Molleson, 2006). Repetitive activity of kneeling while grinding could have led towards chronic knee injuries. Frequent habitual activities of kneeling and/or squatting due to cereal preparation were surely practiced by prehistoric inhabitants of Kneževići - Malo Libinje and these could have resulted in high prevalence of vastus notch observed in this skeletal assemblage.

Today, few distinct defects associated with patella are acknowledged, some of which might be mistaken for bipartite patella and/or vastus notch (Figure 9). In example, dorsal defect of the patella presents a cavitation or a depression on the posterior (dorsal) surface of the bone (Owsley \& Mann, 1990) which distinguishes the condition from vastus notch and bipartite patella, since the latter two only occur on the superolateral side. It is a concave, round-shaped defect and appears to be self-limiting (Resnick \& Niwayama, 1981). Dorsal defect can occur in a conjunction with bipartite patella, or as a separate anomaly (Todd \& McCally, 1921). Another rather rare condition is called a double patella. The term is used for the condition in which the bone is divided into a superior portion and an inferior portion, which usually overlap (Anderson, 2002). The superior portion is usually larger and can occasionally completely overlap the smaller element, resulting in anterior and the posterior patella (Brailsford, 1945). Most commonly, double patella occurs as a part of genetic condition termed multiple epiphyseal dysplasia (Silverman et al., 1993; Sutton, 1998). Lastly, a separate ossicle can be located on the medial border of the patella (Halpren \& Oakley, 1978), appearing to represent an unfused additional ossification center. This, however, is not consistent with Saupe's (1921) classification of bipartite patella and therefore should be observed as a distinct condition. As far as traumas are concerned, injury almost invariably occurs unilaterally, whilst an anatomical condition would more frequently be bilateral (Anderson, 2002). When both patellae are available for examination, it is easier to distinguish a trauma from bipartite patella or vastus notch; when not, defect should be examined for a new bone overgrowth or callus formation that is expected with a healing fracture (Anderson, 2002). 
Based on the provided differential diagnosis, the most probable explanation for the studied conditions observed in the patellae from Malo Libinje is bipartite patella and vastus notch.

\section{Conclusion}

This study presents the first documented case of joint occurrence of bipartite patella and vastus notch in a Croatian skeletal assemblage, but also the largest amount of patellae with vastus notch in an archaeological population from Croatia recorded so far. Conditions associated with patella are sparse in general, so the fact that two similar and at the same time etiologically distinct patellar lesions were recorded at the same archaeological site is rather intriguing. Even rarer find is vastus notch defect observed on the left patella belonging to an adult whose right patella exhibits bipartition at the same time. High prevalence of vastus notch in Kneževići - Malo Libinje assemblage may indicate that these individuals regularly performed activities involving kneeling and/or squatting, possibly associated with some type of manual labor (e.g. cereal grinding and dehusking). In any case, the presented research contributes to the study of these conditions in ancient populations, but also provides a broader insight into the lives of the prehistoric inhabitants of the Velebit Mountain region.

\section{Acknowledgements}

The present study was financially supported by the Croatian Science Foundation grant HRZZ IP-2016-061450.

\section{References}

Adams, J., Leonard, R.D. (1925). A development anomaly of the patella frequently diagnosed as fracture. Surgical Gynaecological Obstetrics, 41, 601-604.

Akdag T., Guldogan E.S., Coskun H., Turan A., Hekimoglu B. (2019). Magnetic resonance imaging for diagnosis of bipartite patella: usefulness and relationship with symptoms. Polish Journal of Radiology, 84, 491-497.

Anderson, J. E. (1963). The people of Fairty: An osteological analysis of an Iroquois ossuary. National Museum of Canada, Bulletin, 193, 128-129.

Anderson, T. (2002). A bipartite patella in a juvenile from a medieval context. International Journal of Osteoarchaeology, 12, 297-302.
Aufderheide, A.C., Rodriguez-Martin, C. (1998). The Cambridge encyclopedia of human paleopathology. Cambridge: Cambridge University Press.

Atesok, K., Nedim Doral, M., Lowe, J., Finsterbush, A. (2008). Symptomatic bipartite patella: treatment alternatives. Journal of the American Academy of Orthopaedic Surgeons, 16(8), 455-61.

Barnes, E. (2012). Atlas of developmental field anomalies of the human skeleton. New Jersey: Wiley-Blackwell.

Bedić, Ž. (2017). Biološke karakteristike kostura pokopanih u Glagoljaškoj ulici u Zadru. Diadora: glasilo Arheološkog muzeja u Zadru, 31, 223-245.

Blumensaat, C. (1933). Patella partita - Traumatische Spaltpatella Patellarfraktur. Archiv für orthopädische und Unfall-Chirurgie, mit besonderer Berücksichtigung der Frakturenlehre und der orthopädisch-chirurgischen Technik, 32, 263-282.

Brailsford, J.F. (1945). The radiology of bone and joints: An introduction to the study of tumors and other diseases of bone. London: Williams \& Wilkins.

Capasso, L., Kennedy, K.A.R., Wilczak, C.A. (1999). Atlas of occupational markers on human remains. Teramo: Edigrafial.

Cunningham, C., Scheuer, L., Black, S. (2000). Developmental juvenile osteology. New York: Academic Press.

Dayal, M.R, Bidmos, M.A. (2005). Discriminating sex in South African blacks using patella

dimensions. Journal of Forensic Sciences, 50, 1294-1297.

Duthie, R.B., Bentley, G. (1996). Mercer's orthopaedic surgery. London: Arnold.

Finnegan, M. (1978). Non-metric variation of the intracranial skeleton. Journal of Anatomy, 125(1), 23-37.

Fazekas, I.G, Kósa, F. (1978). Forensic fetal osteology. Budapest: Akadémiai Kiadó.

George, R. (1935.) Bilateral bipartite patellae. British Journal of Surgery, 22, 555-560.

Glavičić, A. (1982). Nalazi kamenih gromila na Velebitu (I). Senjski zbornik, 9/1, 33-42.

Glavičić, A. (1982a). Prilog istraživanje starohrvatske sakralne arhitekture na primorskim padinama Velebita i Velike Kapele (I). Senjski zbornik, 9/1, 91-114.

Glavičić, A. (1984). Arheološki nalazi iz Senja i okolice (VI). Senjski zbornik, 10-11, 7-28.

Green Jr., W.T. (1975). Painful bipartite patella. A report of three cases. Clinical Orthopaedics and Related Research, 110, 197-200. 
Gruber, W. (1883). In Bildungs anomalie mit bildungs hemmung begründete bipartition beider patellae eines jungen subjektes. Virchows Archive, 94, 358-361.

Halpren, A.A., Hewitt, O. (1978). Painful medial bipartite patellae. Clinical Orthopaedics and Related Research, 134, 180-181.

Indra, L., Vach, W., Desideri, J., Besse, M., Pichler, S.L. (2021). Testing the validity of population-specific sex estimation equations: An evaluation based on talus and patella measurements. Science \& Justice, 61, 555-563.

Inskip, S. (2014). Islam in Iberia or Iberian Islam: social bioarchaeology and the analysis of emerging Islamic identity in Early Medieval Iberia. Unpublished PhD thesis, Southampton: University of Southampton.

Introna Jr., F., Di Vella, G., Campobasso, C.P. (1998). Sex determination by discriminant analysis of patella measurements. Forensic Science International, 95, 39-45.

Kavanaugh, E.C., Zoga, A., Omar, I., Ford, S., Schweitzer, M, Eustace, S. (2007). MRI findings in bipartite patella. Skeletal Radiology, 36(3), 209-214.

Kemkes-Grottenthaler, A. (2005). Sex determination by discriminant analysis: an evaluation of the reliability of patella measurements. Forensic Science International, 147, 129-133.

Kempson, F.C. (1902). Eargination of the patella. Journal of Anatomy and Physiology, 36(4), 419-420.

Kjellström, A. (2004). A case study of os cuneiforme mediale bipartum from Sigtuna, Sweden. International Journal of Osteoarchaeology, 14(6), 475-480.

Kose, O., Eraslan, A., Ergun, A., Egerci, O.F., Ercan, E.C. (2015). Prevalence of bipartite patella in a Turkish population. Analysis of bilateral knee radiographs in 897 subjects. International Journal of Morphology, 33(3), 1108-1113.

L'Abbé, E.N., Coetzee, F.P., Loots, M. (2008). A description of Iron Age skeletons from Pilanesberg National park, South Africa. South African Archaeological Bulletin, 63(187), 28-36.

Mann, R.W., Murphy, S.P. (1990). Regional atlas of bone disease. Springfield: CC Thomas.

Messeri, P. (1961). Morfologia della rotula nei neolitici della Liguria. Archivio per l'Antropologia e l'Etnologia, 91, 1-11.

Messina, A., Sineo, L. (2007). A case of bipartite patella in Paleochristian necropolis in Marsala (Italy). Journal of Paleopathology, 19, 107-115.

Molleson, T. (2006). Hunters of Nemrik. Studies in Historical Anthropology, 3, 5-18.

Molleson, T. (2016). The ordinary Neolithic people of Abu Hureyra, In: Fresh fields and pastures new; Lillios, K.T., Chazan, M. (eds.). Leiden: Sidestone Press, 187-205.
Mullen, G.J., Hoppa, R.D. (1992). Rogers ossuary (AgHb-131): An early ontario Iroquois burial feature from Brantford township. Canadian Journal of Archaeology / Journal Canadien d'Archéologie, 16, 32-47.

O'Brien, J., Murphy, C., Halpenny, D., McNeill, G., Torreggiani, W.C. (2011). Magnetic resonance imaging features of asymptomatic bipartite patella. European Journal of Radiology, 78(33), 425-429.

Oetteking, B. (1922). Anomalous patellae. The Anatomical Record, 23(4), 269-279.

Ogata, K., (1994). Painful bipartite patella. A new approach to operative treatment. The Journal of Bone and Joint Surgery, 76(4), 573-578.

Ogden, R.W. (1984) Non-linear elastic deformations. Chichester: Ellis Horwood.

Okuno, H., Sugita, T., Kawamata, T., Ohnuma, M., Yamada, N., Yoshizumi, Y. (2004). Traumatic separation of a type I bipartite patella: A report of four knees. Clinical Orthopaedics and Related Research, 420, 257-260.

Oohashi, Y., Koshino, T., Oohashi, Y. (2010). Clinical features and classification of bipartite or tripartite patella. Knee Surgery, Sports Traumatology, Arthroscopy, 18(11), 1465-1469.

Ortner, D. J. (2003). Identification of pathological conditions in human skeletal remains. San Diego: Academic Press.

Osterholtz, A., Baustian, K.M., Martin, D.L. (2014). Commingled and disarticulated human remains: Working toward improved theory, method and data. New York: Springer.

Owsley, J.W., Mann, R.W. (1990). Bilateral dorsal defect of the patella. American Journal of Roentgenology, 154(6), 1347-1348.

Paal, H. (1932). Beiträge zur nicht-traumatischen Teilung der Kniescheibe (Patella partita). Deutsche Zeitschrift für Chirurgie, 237, 626-631.

Peckmann, T.R., Meek, S., Dilkie, N., Rozendaal, A. (2016). Determination of sex from the patella in contemporary Spanish population. Journal of Forensic and Legal Medicine, 44, 84-91.

Premužić, Z. (2016). Antropološka perspektiva pogrebnih običaja početka kasnoga brončanoga doba u sjevernoj Hrvatskoj. Zagreb: Filozofski fakultet Sveučilišta u Zagrebu.

Resnick, D., Niwayama, G. (1981). Diagnosis of bone and joint disorders. Philadelphia: WB Saunders.

Rich, J., Dean, D.E., Powers, R.H. (2005). Forensic medicine of the lower extremity. New Jersey: Humana Press.

Rios, L., Kivell, T.L., Lalueza-Fox, C., Estalrrich, A., Garcia-Tabernero, A., Huguet, R., Quintino, Y., de la Rasilla, M., Rosas, A. (2019). Skeletal anomalies in the Neandertal family of El Sidron (Spain) support a role of inbreeding in Neandertal extinction. Scientific Reports, 9(1), (1697). 
Saupe, H. (1921). Beitrag zur patella partita. Fortschritte auf dem Gebiete der Röntgenstrahlen, 28, 37-41.

Scattarella, V., Sublimi Saponetti, S., Laraspata, L., Bartoli, F., Bertoldi., F. (2002). The individual of the early Neolithic of Balsignano (Bari, Italy): A study of some skeletal indicators of stress and palaeonutritional analysis. Journal of Human Evolution, 17, 143 155.

Sim, J.A., Kim, B.K., Lee, B.K., Yoon, Y.C., Choi, E.S. (2016). Arthroscopic reduction of irreducible posterolateral knee dislocation with interposition of the vastus medialis: A case report. Journal of Trauma and Injury, 29(4), 167-171.

Shulman, S. (1955). Unilateral congenital duplication of the patella. British Journal of Radiology, 28(327), 164-165.

Silverman, F.N., Coley, B.D., Kuhn, J.P. (1993). Caffey's pediatric xray diagnosis: An integrated imaging approach. Philadelphia: WB Saunders.

Stephan, V.H., Gill, G.W. (2016). Skeletal biology of the ancient Rapanui (Easter Islanders). Cambridge: Cambridge University Press.

Sutton D. 1998. Textbook of radiology and imaging. New York: Churchill Livingstone.

Šućur, J., Brajković, D., Bedić, Ž., Vyroubal, V. (2020). Pakoštane Maksanova gomila, a newly discovered necropolis of kamici (stećci). In: Life and Death in Mediaeval and Early Modern Times. Proceedings of the 5th International Scientific Conference of Mediaeval Archaeology of the Institute of Archaeology; Krznar S.,
Sekelj Ivančan T., Belaj J., Tkalčec T. (eds.). Zagreb: Institut za arheologiju, 215-238.

Tachdjian, M.O. (1990). Pediatric orthopedics. Philadelphia: WB Saunders.

Todd, T.W., McCally, C.W. (1921). Defects of the patellar border. Annals of Surgery, 74(6), 775-782.

Topić, N., Bedić, Ž., Vyroubal, V., Šlaus, M., Barešić, J., Sironić, A., Ilkić, M., Moore A.M.T., Drašković Vlašić, N. (2019). Inventar nalaza i višefazno groblje uz utvrdu Sokol u Konavlima. Archaeologia Adriatica, 13, 107-251.

Weaver, J.K. (1977). Bipartite patellae as a cause of disability in the athlete. The American Journal of Sports Medicine, 5(4), 137-143.

Weckström, M., Parviainen, M., Pihlajamäki, H.K. (2008). Excision of painful bipartite patella: good long-term outcome in young adults. Clinical Orthopaedics and Related Research, 466(11), 2848-2855.

White, T.E. (1953). A method of calculating the dietary percentage of various food animals utilized by aboriginal peoples. American Antiquity, 18(4), 396-398.

White, T.D., Folkens, P.A. (2005). The human bone manual. San Diego: Elsevier Academic Press.

Wright, W. (1903). Case of accessory patellae in the human subject, with remarks on emargination of the patella. Journal of Anatomy and Physiology, 38(1), 65-67. 